\title{
HOW COVID-19 PANDEMIC HAS AFFECTED THE LIVES AND TRAINING OF SURGICAL RESIDENTS IN MAYO HOSPITAL LAHORE
}

\author{
AYESHA SHAUKAT, BAHZAD AKRAM KHAN, GHAZANFAR ALI, SHUJAT AHMED RIAZ, \\ ASJAD UR REHMAN, SOMER MASOOD \\ Department of Surgery, King Edward Medical University/Mayo Hospital Lahore
}

\begin{abstract}
Objective: To assess how COVID-19 pandemic effect surgical residents in Mayo hospital Lahore in regard of their training and social life.

Methods: It was observational study at Mayo Hospital Lahore. Its duration was four months from May 2020 to August 2020. A study was conducted using online questionnaire on Google docs ${ }^{\circledR}$ containing 25 questions to be filled by residents of surgery and allied surgery of Mayo Hospital Lahore. Residents of general surgery and allied surgical departments working during the COVID-19 pandemic were included in the study. SPSS version 26 was used to analysis. A p-value $\leq 0.05$ was considered significant.

Results: One hundred and two residents responded to our questionnaire from which 83(81.4\%) respondents were male and 19(18.6\%) were female. Out of all, 87(85.3\%) had a fear of contracting COVID-19. 41(40.2\%) get infected with COVID-19 from hospital and 61(59.8\%) remained healthy. In all this scenario of pandemic of covid-19, 95(93.1\%) residents thought that their training suffered a lot during this period as compared to 07(6.9\%) resident who think that their training do not suffered significantly during the pandemic. During this pandemic OPD services were suspended so $79(77.5 \%)$ residents had no exposure to variety of cases and $75(73.5 \%)$ think management in surgical emergency is up to mark. Regression analysis showed that training of residents affected due to reduction in bed-side teaching (pvalue $=0.024)$, decrease in duty hours $(\mathrm{p}$-value $=0.005)$ and reduction in the number of elective surgeries $(\mathrm{p}$-value $=0.045)$

Conclusion: During pandemic of COVID-19, surgical resident of Mayo hospital had fear of contracting disease and carrying to their families. Over all they think that their training has been affected by this pandemic due to shut down of outpatient department, elective lists and bedside teaching in spite of their interest in on line teaching.
\end{abstract}

Key Words: Resident training, COVID-19, social impact, Pandemic

How to cite this article: Shoukat A, Khan BA, Ali G, Riaz SA, Rehman AU, Masood S. How Covid-19 pandemic has affected the lives and training of surgical residents in Mayo Hospital Lahore. Pak Postgrad Med J 2020;31(4): 195-200

This is an Open Access article distributed under the terms of the Creative Commons Attribution License (http://creativecommons.org/licenses/by/3.0), which permits unrestricted use, distribution, and reproduction in any medium, provided the original work is properly cited.

DOI: http://doi.org/10.51642/ppmj.v31i04.369

Correspondence to: Ghazanfar Ali,

Department of Surgery, King Edward Medical

University/Mayo Hospital Lahore, Pakistan.

Email:dr.gznfr@gmail.com

\section{INTRODUCTION}

The 2019 to 2020 coronavirus pandemic is an ongoing pandemic of coronavirus disease 2019 (COVID-19) caused by severe acute respiratory syndrome coronavirus 2 (SARS-CoV-2) ${ }^{1}$. The outbreak was first identified in Wuhan, China, in December 2019². The World Health Organization declared the outbreak a
Public Health Emergency of International Concern on 30th January 2020, and a pandemic on the 11th of March 20203. As of May 1, 2020, more than 3.3 million cases of COVID-19 have been reported in 187 countries and territories, resulting in more than 235,000 deaths ${ }^{4}$. The novel coronavirus and associated COVID19 are spreading rapidly across the globe with rapid growth in Pakistan. Its drastic impact on the world community and global health is massive, evolving and uncertain. The consequences on general surgery departments are primarily indirect, with the termination of all non-essential general surgical treatment being common. Although this is essential for systemsustaining isolation and resource reallocation steps, 
surgical damage is profound ${ }^{5}$. During a pandemic that involves interpersonal spacing, extended periods of isolation, and social involvement to prevent uninhibited spread of the disease, restructuring of the resident aspect of care delivery is essential ${ }^{6}$.

Although patient care is given priority in modern medicine during this ongoing period, residents education continues, particularly in the context of decreased clinical volume. Education is better done online in the specific context of social distance ${ }^{7}$. Numerous readily available teleconferencing apps are user-friendly such as zoom app and allow an entire residency to $\log$ on to a joint video conference at the same time ${ }^{7}$. A faculty leader will then communicate with lecture presentations, case conferences or engaging questions and answer sessions in an active way. It is highly suggested to use video conferencing to help reduce the tension of interpersonal distance that can be produced by such a crisis due to social distancing guidelines ${ }^{8}$. Residents should be granted safe time to engage in key didactic activities ${ }^{9}$. Although it is understood that under some conditions this might not be feasible, resident education should proceed if feasible. In addition, during this period, in the form of virtual technology or simulation training, there may be a place for digital enhancement of surgical education ${ }^{10}$. We believe that as the health system recovers from this epidemic, surgeons will work creatively over hours (evenings / weekends) to keep up with pent-up surgical demand from patients whose elective operations were postponed due to the global recession ${ }^{11}$.

In the light of COVID-19 lockdown where public has been restricted by government and people are staying at home, only COVID-19 positive patients or surgical emergency cases are reporting to surgical emergency of teaching hospital of Lahore. The aim of this study is to assess the effect of this pandemic on the lives of surgical residents of Mayo Hospital in regards to their training, gaining knowledge and surgical skills, bed side teaching, apprehension of getting virus and becoming a carrier of virus to their family.

\section{METHODS}

This study was conducted in Mayo Hospital Lahore and total about 102 residents of surgery and allied surgery were included in this study, which was extended over the period of four months (May 2020 to August 2020). After taking permission from the ethical review committee of university, an online questionnaire on Google docs was distributed among all the residents working in departments of surgery and allied surgical departments. Participation in the study was voluntary. Table 1: Participants response to questionnaire:
This questionnaire had 25-questions about resident's experiences with COVID-19 exposure, fear of transmission of COVID-19 to their families, social distancing, using of social media, telemedicine, learning of surgical and clinical skills, web-based learning, outpatient visits, duty hours, elective and emergency surgery. Demographic data included was: center of training, age, and gender and residency year etc. Statistical analysis carried out with the SPSS version 26 software. The data is categorical and expressed in frequencies and percentages. Keeping the variable "Post graduate-training affected by COVID-19" as the dependent variable (outcome variable), binary logistic regression analysis calculating the p-value performed ( $p$-value $\leq 0.05$ considered significant) and the results are obtained.

\section{RESULTS:}

In this study, total 102 resident doctors participated. $81.4 \%$ were male and $18.6 \%$ were females with the age group of 24 to 28 years of $59.8 \%$ and 29 to 32 years of $40.2 \%$. Specialties include General surgery, ENT, Obstetrics/Gynecology, Maxillofacial surgery, Neurosurgery, Orthopedic Surgery, Urology, Pediatric Surgery, Plastic surgery. Participant's response to questionare is shown in table 1. Demographic variables are shown in table 2 .

Majority had a fear of contracting COVID-19 and almost half of them get infected with COVID-19 from hospital and 61(59.8\%) residents remained healthy. In all this scenario of pandemic of COVID-19, 95(93.1\%) residents thought that their training suffered a lot during this period as compared to 07(6.9\%) resident who thought that their training was not suffered significantly during the pandemic.

Among them $85.3 \%$ had a fear of contracting COVID19. $92.2 \%$ had fear to transmit disease to their family. $41.2 \%$ get infected with COVID -19 from hospital. $62.7 \%$ thought that telemedicine was helpful for the management of patients. During this pandemic OPD services were suspended so $78.4 \%$ had no exposure to variety of cases.72.5\% thought that improvement in their clinical skills of history taking and clinical examination of patients was not as such as before pandemic.

In medical education, bed side teaching in the ward has important role. $79.4 \%$ doctors have opinion that bed side teaching is not same as before pandemic. 53.9\% said there were classes in the ward for their teaching purpose. $57.8 \%$ doctors are doing their research work for their dissertation and thesis. 


\section{Sr. No Questions}

1. Do you think that tele-medicine is helpful for patient's management in department of surgery?

2. Do you have reduced exposure to variety of cases in OPD?

3. Do you think that improvement in your skills of history taking and clinical examination of patients during the pandemic is same as you have appreciated before pandemic?

4. Do you have same kind of your bed-side teaching for the management of patients in the ward during this pandemic as before COVID-19.?

5. Is there still arrangement of classes for trainees in the ward?

6. Are you performing the research work during this pandemic for your dissertation/thesis?

7. Do you get opportunity to interact with the consultant during your duty?

8. Do you have decrease in duty hours in hospital to have limited exposure to suspicious patients of COVID-19 in surgical ward?

9. Do decrease in duty hours have an effect on your learning of clinical/surgical skills?

10. Do you think that patient's management in surgical emergency is up to mark during this period?

11. Do you have to get COVID-19 diagnostic test of suspicious COVID-19 patient before surgery in your emergency?

12. Do you use separate operation theater and adopt full precautions to operate a suspicious patient of COVID-19 in emergency?

13. Do elective surgical procedures are being performed during this pandemic period in your department?

14. Do cancer surgery is being performed in your department during this pandemic?

15. Do you use social media for COVID-19 updates regularly?

16. Have you read journals of surgery to keep your knowledge up-to date during this pandemic?

17. Have you read any surgical textbook to update knowledge during this pandemic?

18. Have you read any standard book of operative surgery during the pandemic?

19. Have you seen more no. of operative surgery videos during this period of pandemic?

20. Have you participated in webinar during this period more frequently?

21. Do you have fear of contracting COVID-19 at workplace?

22. Do you fear of transmitting COVID-19 to your family?

23. Do you get infected with COVID-19 during working at hospital?

24. Do you observe social distancing at work place?

25. Do you use mobile phone with protective covering during your stay at hospital to reduce the chance of getting contamination by COVID-19 from suspected or asymptomatic patients
Yes
No
$41(40.2 \%) \quad 61(59.8 \%)$
$79(77.5 \%) \quad 23(22.5 \%)$
$28(27.5 \%) 74(72.5 \%)$
$06(5.9 \%) \quad 96(94.1 \%)$
$47(46.1 \%) 55(53.9 \%)$
$60(58.8 \%) 42(41.2 \%)$
$80(78.4 \%) \quad 22(21.4 \%)$
93(91.2\%) $9(8.8 \%)$
$80(78.4 \%) 22(21.6 \%)$
$75(73.5 \%) \quad 27(26.5 \%)$
$48(47.1 \%) \quad 54(52.9 \%)$
$67(65.7 \%) \quad 35(34.3 \%)$
$34(33.3 \%) 68(66.7 \%)$
$58(56.9 \%) \quad 44(43.1 \%)$
$71(70.3 \%) \quad 31(29.7 \%)$
$61(59.8 \%) \quad 41(40.2 \%)$
$76(74.5 \%) \quad 26(25.5 \%)$
$66(64.7 \%) \quad 36(35.3 \%)$
$78(77.2 \%) \quad 23(22.8 \%)$
$62(60.8 \%) \quad 40(39.2 \%)$
$87(85.3 \%) 15(14.73 \%)$
94(92.2\%) $\quad 8(7.8 \%)$
$41(40.2 \%) \quad 61(59.8 \%)$
$53(52.0 \%) \quad 49(48 \%)$
$31(30.4 \%) \quad 71(69.6 \%)$

Table 2.

\begin{tabular}{llccc}
\hline $\begin{array}{c}\text { Demographic } \\
\text { variables }\end{array}$ & \multicolumn{1}{c}{ Groups } & $\mathrm{N}$ & $\%$ & $\begin{array}{c}\text { P-value } \\
<0.05\end{array}$ \\
\hline \multirow{2}{*}{ Age } & $24-28$ & 58 & 56.8 & .018 \\
\hline \multirow{2}{*}{ Gender } & $29-32$ & 44 & 43.2 & \\
\hline \multirow{6}{*}{ Participant } & Male & 83 & 81.4 & .612 \\
& Female & 19 & 18.6 & \\
\hline \multirow{5}{*}{ specialty } & Ent & 6 & 5.9 & \\
& General Surgery & 66 & 64.7 & \\
& Gynaecology & 3 & 2.9 & \\
& Oeurosurgery & 3 & 2.9 & \\
& Oro-Maedics & 3 & 2.9 & 0.934 \\
& Surgery & 6 & 5.9 & \\
& Paediatric Surgery & 5 & 4.9 & \\
& Plastic Surgery & 7 & 6.9 & \\
& Thoracic Surgery & 1 & 1 & \\
\hline & Urology & 2 & 2 & \\
\hline
\end{tabular}

For the better management of patients in the department 78.4\% residents have interacted with the consultant. $91.2 \%$ confirmed that they had decreased duty hours in the department so that they could have limited exposure to the suspected patients of COVID-19 to be infected by the virus.79.2\% thought that relaxation in duty hours had badly affected their training. Social Distancing is important to prevent the spread of disease so $52 \%$ residents are maintain social distance at work place. During duty hours in the hospital only $30.7 \%$ doctors used protective covering for their phones to protect it from being infected by the virus from the patients. Social media is very important source of information so 70.3\% used it for covid-19 updates to keep their knowledge up to-date. During this pandemic 59.8\% residents have read the medical journals. To increase in your back ground knowledge $74.5 \%$ have read standard text book of surgery. Operative surgery can be improved by assisting watching or by seeing operative video. 77.2 
$\%$ resident watched video of surgical procedure. To gain knowledge webinars become one of the modes of expressing and sharing of knowledge. As most of the resident had access to internet and had smart phones so it is not difficult to attend webinar for them and $60.8 \%$ participated in different webinars. In surgery emergency duties are an important part of training of resident. In causality duty $60.8 \%$ residents have used N-95 mask as protective measure. $73.5 \%$ thought that management in surgical emergency is up to mark. In emergency surgery only $52.9 \%$ residents confessed to perform COVID-19 screening prior to surgery. Mostly elective surgeries are postponed in this pandemic of COVID-19 so $66.7 \%$ resident confirmed that no elective surgeries are being performed in their departments. In spite of COVID-19, $56.9 \%$ residents said that cancer /oncological surgeries were being performed in their departments. In all this scenario of pandemic of COVID-19, 93.1\% residents thought that their training suffered a lot during this period.

Table 3: Regression analysis of variables effecting surgical training of residents

\begin{tabular}{llc}
\hline Sr. No & Variables & $\begin{array}{c}\text { P-Value } \\
(\text { sig. } \leq 0.05)\end{array}$ \\
\hline 1. & Reduction in exposure to variety of & 0.694 \\
& cases & \\
2. & Decrease in clinical skills & 0.353 \\
3. & Reduction in bed-side teaching & 0.024 \\
4. & Decrease in number of teaching classes & 0.489 \\
5. & Decrease in Research work & 0.113 \\
6. & Decrease in clinical discussion with & 0.631 \\
& consultant & 0.005 \\
7. & Decrease in duty hours & 0.896 \\
8. & Quality of Patients' management in & \\
& Emergency & 0.045 \\
9. & Reduction in no. of Elective Surgery & 0.974 \\
10. & Fear of contracting COVID-19 \\
\hline
\end{tabular}

During this pandemic OPD services were suspended so $79(77.5 \%)$ residents had no exposure to variety of cases and $75(73.5 \%$ ) think management in surgical emergency is up to mark. As the elective surgery is concerned $68(66.7 \%)$ residents confirmed that no elective surgeries are being performed in their departments. It was found in the regression analysis that there had been a Reduction in bed-side teaching (p-value $=0.024)$, Decrease in duty hours ( $\mathrm{p}$-value $=0.005$ ) and reduction in the number of elective surgeries ( $\mathrm{p}$-value $=0.045$ ). Regression analysis is shown in table 3.

\section{DISCUSSION}

According to our results, to minimize the risk of exposure, the total number of working hours for residents has been substantially decreased. Secondly, the government's timely steps are so far helping to keep the number of patients with COVID-19 lower, as residents are not yet expected to increase the workforce of intensive care units or isolation centers. This gives more opportunity to surgical residents for other educational ventures such as reading textbooks or books on operative surgery to keep their knowledge updated; similar sentiments have been expressed by surgical residents in the United States as can be seen in the study done by Aziz $\mathrm{H}$. et al. ${ }^{14}$ Despite all the preventive measures, our study reports a high percentage of fear of acquiring infection among the residents to a point that it could possibly affect their clinical encounter as evident by a descriptive research conducted in China by Ren S.Y. et al ${ }^{12}$ where they found that if the disease interferes with the doctors' professional capacity, there is a high chance of missing diagnosis or misdiagnosis. The surgical residents in the Mayo Hospital showed that they are concerned about the health of their family as has been seen in a similar study on surgical residents in Boston Massachusetts by $\mathrm{He} \mathrm{K}$. et $\mathrm{al}^{13}$. During patient meetings as well as during surgical procedures where vision, hands and brain should function simultaneously, these fears could be sufficient to impair the rational decision making process ${ }^{12}$ of the doctors as most of them often strive to observe social distances at work and a large percentage of them have been infected with disease.

Overall, our research reported that the COVID-19 outbreak has greatly influenced the regular general surgical practice as well as the routine exposure of residents to both clinical and surgical training activities. The strong decline in the involvement of residents in outpatient visits can be clarified by an imposed global interruption in many surgical areas e.g., all nononcological diseases. A serious shortage of health care workers necessary to care for an enormous influx of patients has been generated in some countries by the rapidly spreading disease. Extreme overwork has resulted in medical staff becoming physically, psychologically and emotionally exhausted. The decline in the participation of residents in diagnostic activities may be attributable to the delay of non-urgent operations, partly due to the higher percentage of consultant general surgeons conducting such activities during the emergency, aimed at reducing the amount of health workers linked to hospital-activity. Similarly, given the recent guidelines to restrict surgical procedures to experienced surgeons, the decline in 
resident exposure to all surgical activities can be explained. In addition, the suspension of all deferrable procedures, with the resultant decline in daily surgical activity, further helps to understand this result. ${ }^{16}$

Finally, our research found that although training in "clinical" activities (outpatient visits and diagnostic procedures) was seriously impaired in all residents, their exposure also decreased dramatically in all surgical activities. Simply put, these are the residents whose training was more seriously affected by the COVID-19 pandemic, while they use interactive multimedia to enhance their learning and study books as well ${ }^{14}$. This result is even more significant, given that in the last years of residency, not only there is a greater exposure to surgery, but those residents will take up jobs earlier.

We have a couple of research limitations. Firstly, we have not tested how successful tele conferences and lectures are. This argument should require more researches to be performed in this regard. Secondly, this research is a single government institution survey and in the middle of this pandemic, more detailed multiinstitutional surveys should be undertaken covering both private and public sector institutions.

\section{CONCLUSIONS}

In conclusion, our study is providing insights on how the COVID-19 pandemic affected the training of surgical residents. Our study showed that there was an overall decrease in residents' training activities from both clinical and surgical perspectives. They had decrease exposure to new cases and decrease operative skills.

Real-life data provide the foundation to implement strategies aiming to continue the training of surgery residents during emergency periods such as the COVID19 pandemic. In this regard, to keep the exposure of residents to this activity, strategies taking advantage of telemedicine should be implemented adapting educational delivery to optimize training and safety during the pandemic, as well as of simulation and smart learning educational programs, including tele mentoring of surgical procedures, might be the key to reach these goals.

\section{CONFLICT OF INTEREST}

Authors declared no conflict of interest.

\section{DISCLOSURE}

Authors have nothing to disclose.

\section{FUNDING}

No funding taken from any source.

\section{PARTICIPANTS' CONSENT}

Informed consents obtained from all individual participants included in the study.

\section{ETHICAL APPROVAL}

The study was approved from Institutional Review Board of King Edward Medical University, Lahore, Pakistan, vide reference No. 463/RC/KEMU, dated July 10, 2020.

\section{REFERNCES}

1. World Health Organization. Naming the coronavirus disease (COVID-19) and the virus that causes it. 2020. URL https://www. who. int/emergencies/diseases/ novel-coronavirus-2019/technical-guidance/namingthe-coronavirus-disease-(covid-2019)-and-the-virusthat-causes-it. 2020.

2. "Coronavirus very likely of animal origin, no sign of lab manipulation: WHO”. Reuters. 21 April 2020. Retrieved 1st May 2020.

3. WHO Coronavirus disease (COVID-2019) situation reports. https://www.who.int/emergencies/diseases/no vel-coronavirus-2019/situation-reports. Accessed May 1,2020

4. Lau S, Luk H, Wong A, Li K, Zhu L, He Z, et al. Possible Bat Origin of Severe Acute Respiratory Syndrome Coronavirus 2. Emerg. Infect. Dis. 2020;26 (7):1542-1547.

5. Schwartz A, Wilson J, Boden S, Moore T, Bradbury $\mathrm{T}$, Fletcher N. Managing Resident Workforce and Education During the COVID-19 Pandemic. JBJS Open Access. 2020;5(2): $\mathrm{e} 0045$.

6. Hellewell J, Abbott S, Gimma A, Bosse NI, Jarvis CI, Russell TW. Feasibility of controlling COVID-19 outbreaks by isolation of cases and contacts. Lancet Glob Health. 2020.

7. Kudrna D. Mental and Ontological Simulacra: NonRationality and Non-Reality in Works by Philip K. Dick. 2020.

8. Thomson G. COVID-19: Social distancing, ACE 2 receptors, protease inhibitors and beyond? International journal of clinical practice. 2020.

9. Daniels AH, Grabel Z, DiGiovanni CW. ACGME accreditation of orthopaedic surgery subspecialty fellowship training programs. J Bone Joint Surg. 2014;96(11):e94.

10. Logishetty K, Gofton WT, Rudran B, Beaulé PE, Cobb JP. Fully immersive virtual reality for total hip arthroplasty: objective measurement of skills and transfer of visuospatial performance after a competency-based simulation curriculum. J Bone Joint Surg. 2020;102(6):e27.

11. Logishetty K, Rudran B, Cobb JP. Virtual reality training improves trainee performance in total hip 
arthroplasty: a randomized controlled trial. Bone Joint J. 2019 ;101(12):1585-1592.

12. Ren SY, Gao RD, Chen YL. Fear can be more harmful than the severe acute respiratory syndrome coronavirus 2 in controlling the corona virus disease 2019 epidemic. World J Clin Cases. 2020 ;8(4):652.

13. He K, Stolarski A, Whang E, Kristo G. Addressing General Surgery residents' concerns in the early phase of the COVID-19 pandemic. J Surg Educ. 2020.

14. Aziz H, James T, Remulla D, Sher L, Genyk Y, Sullivan ME, et al. Effect of COVID-19 on surgical training across the United States: a national survey of general surgery residents. J Surg Educ. 2020.

15. Coyan GN, Aranda-Michel E, Kilic A, Luketich JD, Okusanya O, Chu D, et al. The impact of COVID-19 on thoracic surgery residency programs in the US: A program director survey. J. Card. Surg.2020.
16. Bambakidis NC, Tomei KL. Impact of COVID-19 on neurosurgery resident training and education. $J$ Neurosurg. 2020;1(aop):1-2.

\section{AUTHOR'S CONTRIBUTIONS:}

AS: Concept, Design, Manuscript Writing, Proof Reading

BAK: Drafting, Design, Manuscript Writing

GA, SAR, AUR, SM: Drafting, Design, Data

Collection 